\title{
The Application and Research of Three-Dimensional Form Graphic Design
}

\author{
Yuan zhang, Haimei liu \\ ${ }^{1}$ Hebei Chemical \& Pharmaceutical Vocational Technology College, Shijiazhuang, Hebei, China \\ aYuanzhang@163.com
}

Keywords: Planar Design, Three-Dimensional Configuration, Two-Dimensional Shape

\begin{abstract}
Based on the practical application of three-dimensional form design thinking and design concept, the article is based on $3 \mathrm{~d}$ design in real life for the development of the specific circumstances. Rational and actively from the perspectives of vector-borne and material innovation prospects the $3 \mathrm{~d}$ design in the future in the field of graphic design, objective and fair to show a three-dimensional form design to graphic design great far-reaching influence, so to speak a $3 \mathrm{~d}$ world cannot leave the three dimensional design approach. And this way is the same to broaden and improve the world.
\end{abstract}

\section{Introduction}

The reality of economy and the rapid development of science and technology culture, clearly pointed out that in under the force of the development. There are qualitative changes in the field of graphic design today [1]. The traditional design method of two-dimensional form as the main means cannot meet the demand of people. It is no longer fit the reality of economic development. Conform to the trend of The Times and growing of the three-dimensional form design concept more and play more important role in graphic design, compared with the two-dimensional shape of traditional design concept. It brought people a lot of imagination, appear to be more spiritual designers have to resort to design concept at the same time [2]. The teaching framework of graphic design is seen as Fig. 1. The $3 \mathrm{~d}$ design concept to expand people's horizons and fits all aspects of people's life is the product of the era of progress also ushered in the era.

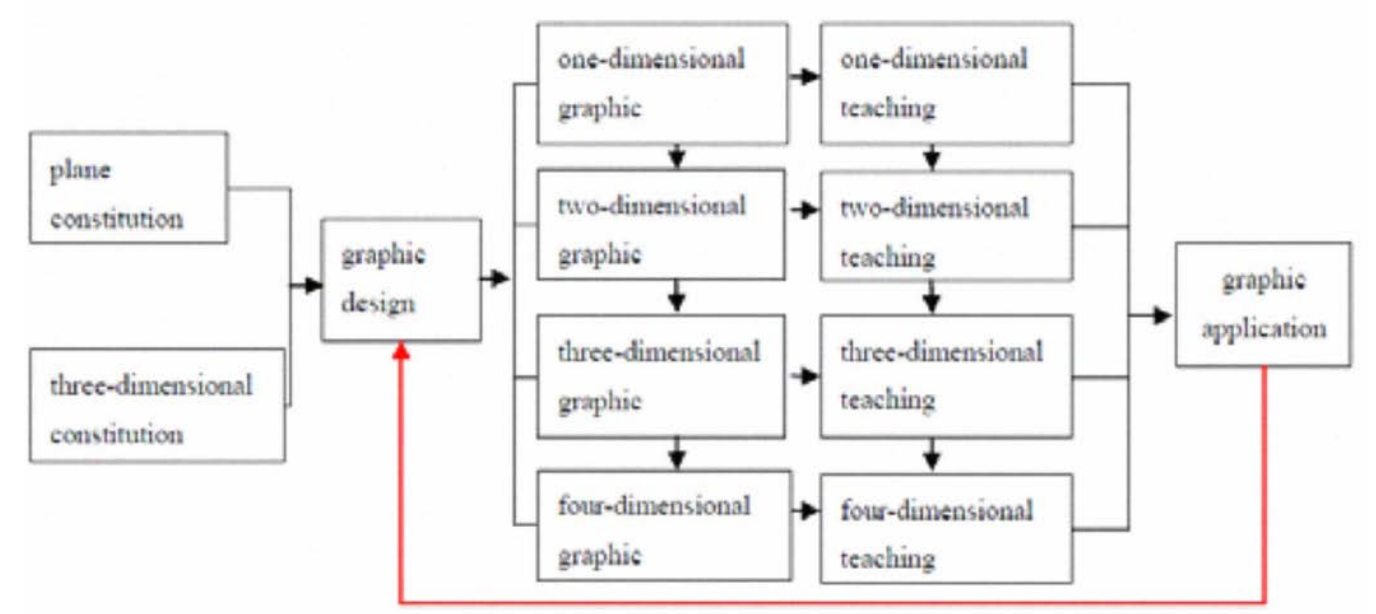

Fig. 1. The teaching framework of graphic design

On the basis of the concept of three-dimensional shape, combined with the reasons and characteristics of this paper to the design of this new way has carried on the classification based on the actual situation in the field of graphic design in real life [3]. It is objectively analyzed compared with the traditional way has unique advantages and inevitable disadvantage, explicitly pointed out that in today's rapid economic development. People for the spiritual and cultural requirements 
standard significantly increased. New media above major premise of the new material emerge in endlessly, only $3 \mathrm{~d}$ design concept to better interpret the consists of $3 \mathrm{~d}$ the diversity of the world.

\section{The Generality about Three-Dimensional Configuration}

We live in a world dominated by the three dimensional space of stereoscopic. Any object from a different perspective will show different spatial form. $3 \mathrm{~d}$ is made up of two dimensional, expression in $2 \mathrm{~d}$ plus one dimension is $3 \mathrm{~d} .2 \mathrm{~d}$ is two directions of the crisscross [4]. $3 \mathrm{~d}$ is stereo. It is produced according to the viewpoint of the mobile space. The so-called stereo feeling is relatively and not absolute. Two-dimensional shape form of planar formation and color composition as the basis of graphic design and $3 \mathrm{~d}$ shape form is direct evolutionary relationships. A modern designers are to express their creative ideas. The performance of the two-dimensional space design means alone cannot satisfied the demand of practical design and highlights the three-dimensional space the stereo modelling of unique advantages through the three dimensional space category $3 \mathrm{~d}$ shape to represent the other side of the plane design. Examples of noise figure circles and power gain circles are seen as Fig. 2. Speak here of the three-dimensional shape not only refers to the three-dimensional modelling and $3 \mathrm{~d}$ graphics in the application of graphic design form.

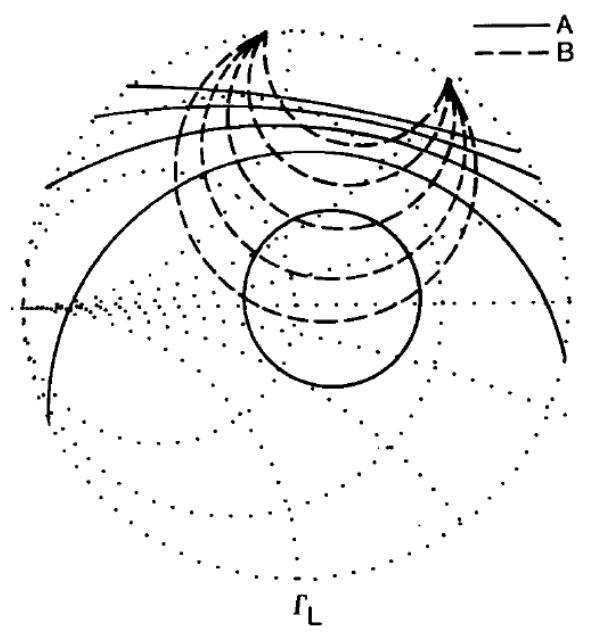

Fig. 2. Examples of noise figure circles and power gain circles

Understanding three-dimensional form is the basis of $3 \mathrm{~d}$ graphic design application. The whole process is a three-dimensional form of segmentation to combination or combination to split. The process of dot, line face three elements is the foundation of any morphogenetic even the final structure. Through to the point, line and plane three-dimensional shape of science, so that the back and tie-in combination to create a new pattern of the object, using different materials and processing technology form the unique three-dimensional effect of three dimensional form. To understand the connotation of the three-dimensional shape can provide designers with a steady stream of design concept. It is also the theoretical basis of all kinds of art and design disciplines, occupies the important position in the graphic design. Three-dimensional form namely stereoscopic form. The stereo configuration not only refers to the structure of the external performance. More refers to the works in graphic design $3 \mathrm{~d}$ graphical modelling form.

Due to the development of modern science and technology. Science and technology as the first productive force of promoting social progress, the development of science and technology is to promote the technological innovation of modern design industry, especially with the coming of information age and the wide application of multimedia technology. To enrich the forms of graphic design extension prompts the three-dimensional graphic design in the form of emerging. Designers in the face of the new multimedia technology and communication platform is to rely on the designer's occupational intuition, to fully grasp and use of new technology brings the innovation of the application. Do the best for their graphic design applications. In turn, the new design idea was to 
reconsider the brain and mind. The pursuit to graphic design more perfect form is found in the emerging new technology innovation in the future may be more excellent performance. Conversion to the actual design application prompts his own design concept and design thinking to keep pace with The Times and constant progress.

\section{Three-Dimensional Form Design in the Plane Design Theory Basis}

Graphic design is the most important. The key is must follow meet the psychological feelings, convey the object so as to create a beautiful artistic conception. How to make the $3 \mathrm{~d}$ shape using better play to put to good use in the plane design. This needs us designer to do the following several aspects. Breakthrough doctrine set and throw an armchair strategist, behind closed doors. As designers we must first cultivate free creative thinking quality and expand their horizons, as the only standard to verify the design concept in practice. Chaotic graphic elements deconstruction is seen as Fig. 3. Don't be an armchair strategist and constrained text expression, not rigid practices ready-made principles and concepts to deal with the problems in the design process.

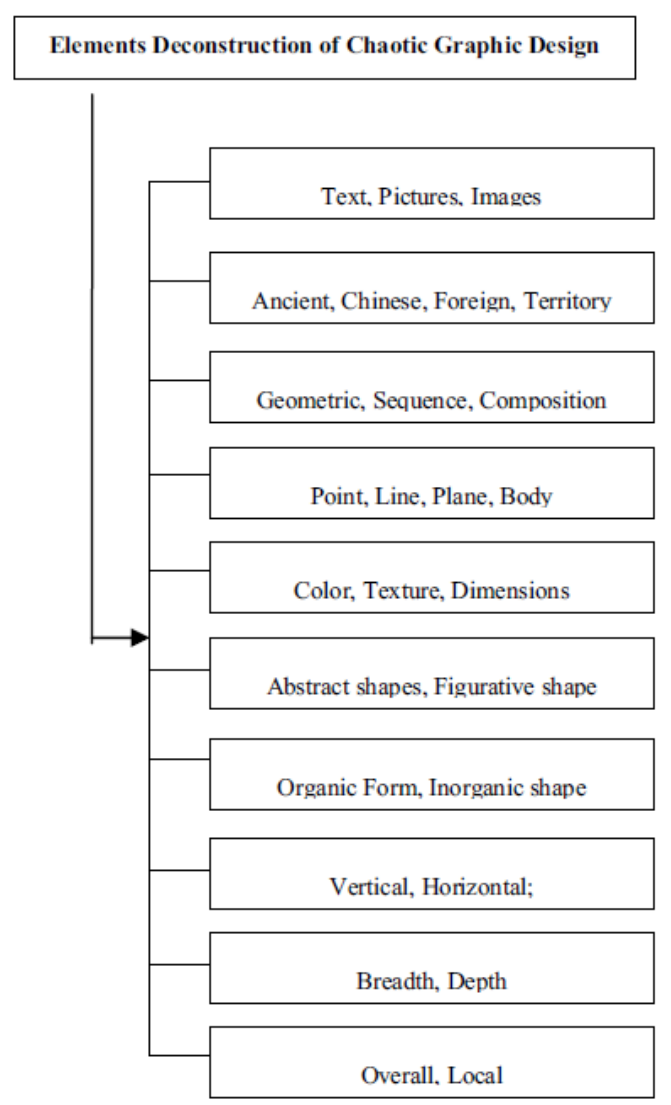

Fig. 3. Chaotic graphic elements deconstruction

Design thinking should be beyond self and beyond the conventional. But only if the function, the relationship between modelling and technology must be coordinated. That is to say, the application of three-dimensional shape in planar design, regardless of how novel or break the routine is based on the functional requirements of graphic design, graphic design and rely on advanced science and technology to be realized. Creative began in demand and consumption demand oriented. A good attractive design, it must be urgently required by people for the market need. The demand of the market is the essence of the design to produce power. Luxuriant design again, if no one is that it need not the value of existence. But note that the so-called market need here has many meanings, for example it is also the design of a house ordinary citizens would want its design durable. Religious people will want to reflect the myth color. Artist hope is unique. Businessmen will want grandeur or attract eyeball. So at the beginning of the design need to consider to be clear about their designs for 
what kind of crowd to determine what they need is the use of specific value or abstract spirit to enjoy to determine the whole design style and direction. The eye produced with graphic lib is seen as Fig. 4.

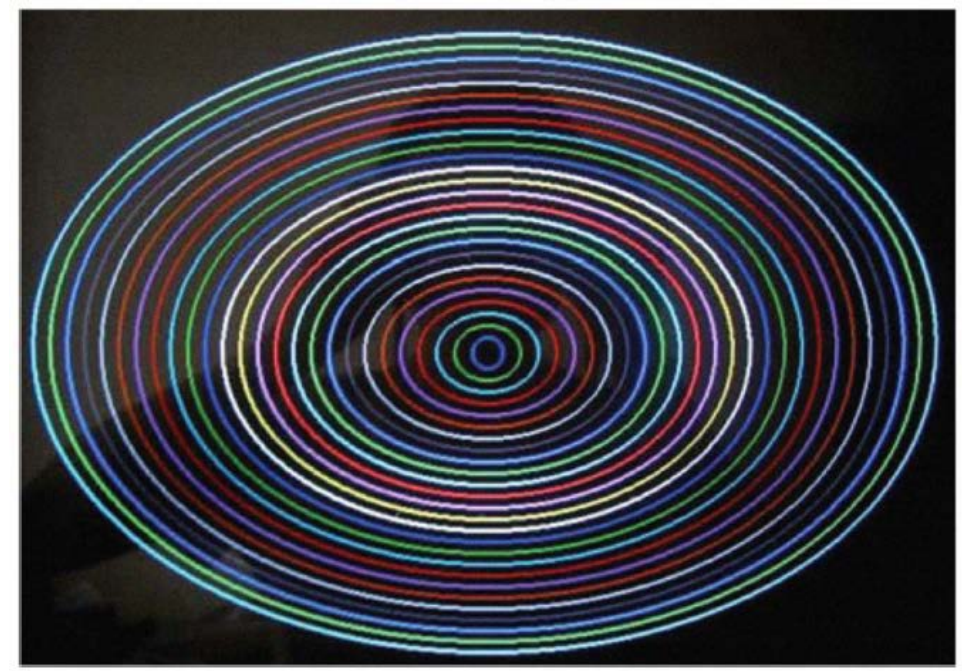

Fig. 4. The eye produced with graphic lib

It has always been a good graphic design must be able to put the people's growing material requirements and pleasure of life to realize the combination of maximum limit and make it meet the needs of the development of social economy. Both at the same time to meet the needs of people aesthetic itself. Three-dimensional shape of the plane design should not only by simple mechanization of indifference, but in harmony with the social development and scientific and technological progress, fusion and pay attention to the era of humanized product. People of the new era, aesthetic temperament and interest in change also now than any time in the history of social more clearly aware that as meaning and value of the existence of the subject. In order to better highlight the essence of human nature, human rights, personality and human aesthetic also increasingly free and complicated.

\section{Conclusions}

Compared with the traditional creation technique, three-dimensional form design broke through a two-dimensional form images and graphics and artistic conception by intertwined across dimensions show greater sense of reality. It is not a static image information, vivid and dynamic is the style of it. In the same way, on the production technology and production material it has more choices and creativity. It all depends on in today print AD design. Three-dimensional design concept has a unique advantage of the form. Graphic design is discussed in this paper has a detailed shown in the various fields of superiority, but also an objective analysis of the design of an emerging technique in the background of the current society. The three dimensional shape shown some disadvantages.

\section{References}

[1] T. Huang, The plane design to expand the research in three dimensional space, Packaging Engineering, 18(24), 2011, 74-78.

[2] P. He, The influence of three-dimensional advertising to plane advertisement design exploration, The Mass of Literature and Art, 21(36), 2011, 36-38.

[3] X. Zhang, Hyper plane advertisement design, Art and Design, 42(35), 2010, 12-15.

[4] F. Sun, In the two-dimensional plane design three dimensional visual space, Art Observatory, 75(52), 2010, 41-45. 